\title{
Поверхностные наноструктуры, формирующиеся на ранних стадиях металл-стимулированного химического травления кремния. Оптические свойства наночастиц серебра
}

\author{
(С) Ю.А. Жарова, В.А. Толмачев, А.И. Бедная, С.И. Павлов
}

Физико-технический институт им. А.Ф. Иофрфе Российской академии наук, 194021 Санкт-Петербург, Россия

E-mail: piliouguina@mail.ioffe.ru

(Получена 11 июля 2017 г. Принята к печати 19 июля 2017 г.)

\begin{abstract}
Работа, состоящая из двух частей, посвящена исследованию наноструктур, формирующихся в 3-стадийном процессе металл-стимулированного химического травления кремния. В первой части исследован процесс химического осаждения слоя самоорганизующихся на поверхности кремниевой пластины наночастиц $\mathrm{Ag}$ (первая стадия металл-стимулированного химического травления). Этот слой является, с одной стороны, катализатором для проведения последующего травления кремния, а с другой - служит своеобразной маской для формирования той или иной топологии формирующихся нанонитей $\mathrm{Si}$. C помощью растрового электронного микроскопа исследована морфология слоя наночастиц серебра (толщиной 40-60 нм), а с помощью спектральной эллипсометрии $(\lambda=250-900$ нм) измерены спектры эллипсометрических углов нанослоев $\Psi$ и $\Delta$. На основе этих спектров определена комплексная диэлектрическая функция полученного слоя Ag с характерным пиком плазмонного резонанса в УФ-части спектра. Исследования оптических свойств слоев нанонитей $\mathrm{Si}$, формирующихся на ранних стадиях металл-стимулированного химического травления, будут опубликованы во второй части работы (в отдельной статье).
\end{abstract}

DOI: 10.21883/FTP.2018.03.45617.8684

\section{1. Введение}

В настоящее время наноструктурированный кремний является важным и многообещающим материалом в развитии кремниевой индустрии, особенно в таких ее областях как наноэлектроника [1], оптоэлектроника [2], биомедицина [3] и используется для разработки устройств преобразования энергии (солнечные батареи [4] и литий-ионные аккумуляторы [5]), био- и химических сенсоров [6].

Существуют разные методы создания наноструктурированного кремния, среди которых можно выделить металл-стимулированное химическое травление кремния (MCXT - metal-assisted chemical etching (MACE)) [7], интерес к которому (см. обзор в [8]) обусловлен тем, что слои кремниевых нанонитей (КНН) состоят из монокристаллического кремния, и для него не требуется дорогостоящее оборудование. Метод МСХТ основан на селективном химическом вытравливании кремния с использованием осажденных/напыленных частиц благородного металла в качестве катализатора и состоит из трех стадий: на первой стадии производится осаждение наночастиц металла, далее происходит травление в растворе на основе НF (вторая стадия МСХТ), а на заключительной третьей стадии удаляется катализатор. При этом электрохимические реакции (окислительно-восстановительные) протекают непосредственно под частицами металла, который является источником положительно заряженных ионов, необходимых для травления кремния. Кремний, не покрытый частицами, остается не протравленным (рис. 1) и, как результат, формируется слой нитеобразной структуры из $c$-Si.
Топология кремниевых нитеобразных структур в процессе травления обеспечивается заранее нанесенными частицами металла. В этой связи для получения заданных параметров кремниевых нитеобразных структур требуется умение управлять размерами и плотностью нанесения наночастиц. Поскольку частицы металла и получаемой $\mathrm{Si}$-структуры имеют размеры порядка нескольких десятков нанометров, для их характеризации требуются высокочувствительные методики. Оптическая эллипсометрия [9] относится к таким методам (к тому же неразрушающим) и позволяет определять толщину и оптические характеристики материалов, в том числе диэлектрические функции. С помощью спектральной эллипсометрии нанослои $\mathrm{Ag}$, полученные с помощью вакуумного напыления на Si-подложке, ранее были исследованы в работах [10-12]. Следует отметить, что морфология частиц, осаждаемых с помощью электроннолучевого или магнетронного распыления, отличается от морфологии наночастиц $\mathrm{Ag}$, которые были получены в нашей работе с использованием химического осаждения серебра из раствора, а эллипсометрические

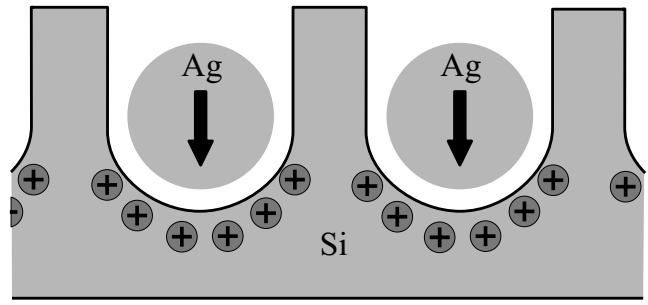

Рис. 1. Схема процесса металл-стимулированного химического травления $\mathrm{Si}$ под частицей металла с образованием кремниевых нитей из $\mathrm{Si}$-подложки. 
исследования таких слоев наночастиц $\mathrm{Ag}$ в литературе не обнаружены.

Цель настоящей работы - получение слоя наночастиц серебра, формирующегося на первой стадии процесса МСХТ, исследование его морфологии и оптических свойств с использованием спектральной эллипсометрии.

\section{2. Методика эксперимента}

$\mathrm{B}$ работе использовались кремниевые пластины $p$-Si (100) с удельным сопротивлением 1 Ом · см. Перед нанесением металла пластины подвергались стандартной отмывке в перекисно-аммиачном и кислото-перекисном растворах. Наночастицы серебра осаждались из раствора $\left(\mathrm{AgNO}_{3}+\mathrm{HF}\right)$ в течение $30 \mathrm{c}$. Микроскопические изображения были получены с помощью растрового электронного микроскопа (РЭМ) JSM 7001F (Jeol, Япония). Оптические измерения проводились с помощью спектрального эллипсометра „Спектроскан“ [13] в диапазоне длин волн $\lambda=250-900 \mathrm{Hм}$, на воздухе, при углах падения излучения относительно нормали к поверхности $\varphi$. Определялись эллипсометрические углы, $\Psi_{\exp }$ и $\Delta_{\exp }$, которые входят в основное уравнение эллипсометрии (1) [14]:

$$
\rho=r_{p} / r_{s}=\operatorname{tg} \Psi \cdot \exp (i \Delta),
$$

где $\operatorname{tg} \Psi=\left|r_{p}\right| /\left|r_{s}\right|$ - относительное изменение комплексных коэффициентов отражения, а $\Delta=\delta r_{p}-\delta r_{s}$ относительное изменение фазы, испытываемое при отражении между $p$ - и $s$-компонентами.

Уравнение (1) является прямой задачей эллипсометрии, с помощью которого можно рассчитывать и анализировать поведение эллипсометрических углов для разных моделей оптических структур исходя из их материальных параметров и углов падения.

\section{3. Исследование слоев наночастиц серебра на поверхности кремния}

После обработки в растворе $\mathrm{AgNO}_{3}+\mathrm{HF}$ на поверхности $\mathrm{Si}$ формируется слой самоорганизующихся частиц серебра островкового типа (рис. 2). Они имеют примерно одинаковую высоту (40-60 нм), некоторый разброс по форме и соответственно по размерам (от 30 до $100 \mathrm{Hм})$. Видимые промежутки между частицами серебра являются своеобразными „зародышами“ вершин образующихся затем вертикальных нитеобразных кремниевых структур (рис. 1). Путем анализа изображений, представленных на рис. 2, $a$, были установлены усредненные размеры межчастичных промежутков в пределах 10-20 нм. Следовательно, можно ожидать формирование кремниевых нитеобразных структур приблизительно с таким же сечением нитей на последующей стадии МCXT.
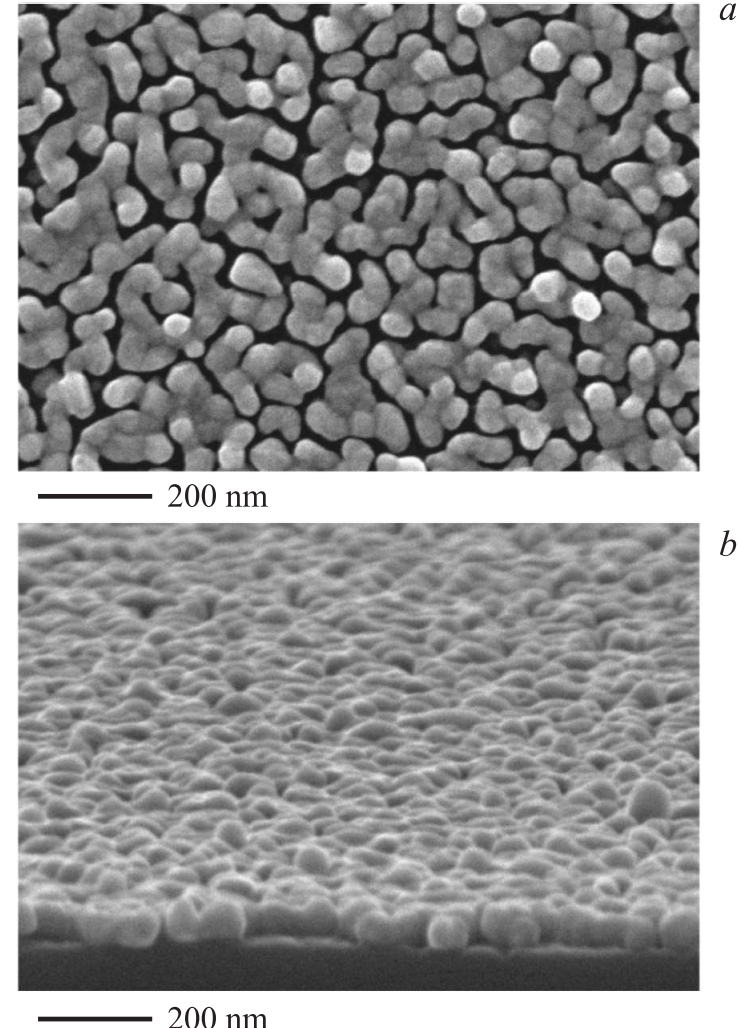

Рис. 2. РЭМ изображения слоя химически осажденных наночастиц серебра на поверхности кремния: $a-$ вид сверху, $b-$ под углом $25^{\circ}$.

На рис. 3 представлены измеренные эллипсометрические углы $\Psi_{\exp }$ и $\Delta_{\exp }$ образцов с нанесенными наночастицами серебра. По сравнению со спектрами исходной поверхности кремния, вычисленными по данным из справочника [15], они изменились радикально. На этом же рисунке для сравнения представлены спектры эллипсометрических углов $\Psi$ и $\Delta$ для серебра, вычисленные исходя из показателей преломления $n$ и показателей поглощения $k$ из [15] и использования модели полубесконечной среды. Спектр $\Psi_{\exp }$ для осажденного слоя $\mathrm{Ag}$ существенно отличается от вычисленного спектра, тогда как для спектра $\Delta_{\exp }$ зависимости достаточно близкие. На спектрах можно отметить наличие характерных пиков в области $\lambda \sim 300$ нм, но не совпадающих по положению и сильно отличных по форме. Одной из возможных причин может быть влияние толщины осажденного слоя Ag на подложке $\mathrm{Si}$. Допустим, что этот слой имеет небольшую толщину и(или) является не сильно поглощающим, тогда падающее излучение будет взаимодействовать также и с подложкой и в результате в отраженном пучке может содержаться отклик и от нее. На вычисленных (а также измеренных) спектрах $\Psi$ и $\Delta$ для $\mathrm{Si}$ видны характерные особенности в области длин волн $\lambda=290$ и 365 нм (рис. 3), которые соответствуют структуре $c$-Si в области $E_{0}=3.4$ эВ в так называемых критических точках [16]. На спектрах $\Psi_{\exp }$ и $\Delta_{\exp }$ для 

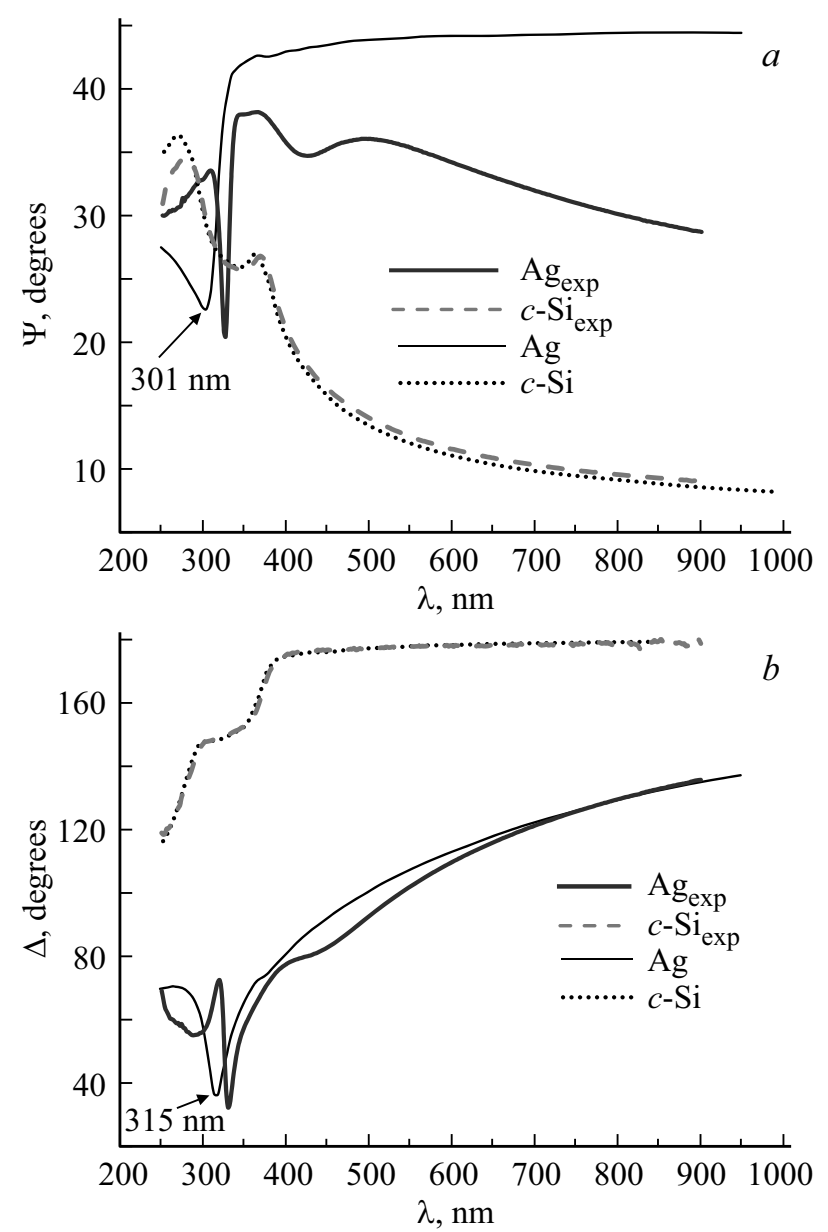

Рис. 3. Спектры измеренных эллипсометрических углов $\Psi_{\exp }(a)$ и $\Delta_{\exp }(b)$ для исходной поверхности кремния $\left(\mathrm{Si}_{\mathrm{exp}}\right)$, слоя с осажденными наночастицами серебра $\left(\mathrm{Ag}_{\mathrm{exp}}\right)$ и вычисленные спектры по параметрам $c$ - $\mathrm{Si}$ и $\mathrm{Ag}$ из справочника $[15]$; угол падения $\varphi=70^{\circ}$.

слоя Ag наличие признаков этих критических точек не обнаружено.

На основании этого можно считать, что глубина проникновения излучения в слой серебра не превышает его толщины, что приводит к оптическому экранированию поверхности кремния. В этом случае, можно использовать модель, в рамках которой излучение, падающее из воздуха, взаимодействует с полубесконечной средой, в нашем случае это композитная среда состоящая из „наночастиц $\mathrm{Ag}$ и воздуха“. Из измеренных двух эллипсометрических параметров $(\Psi$ и $\Delta)$ и определенного угла падения $\varphi$ можно однозначно определить значение комплексной диэлектрической проницаемости $\varepsilon$ (действительную $\varepsilon_{1}$ и мнимую $\varepsilon_{2}$ части) этой среды из выражения [14]

$$
\begin{aligned}
\varepsilon & =\varepsilon_{1}+i \varepsilon_{2} \\
& =\sin ^{2}(\varphi)\left\{1+\left[(1-\rho)^{2} /(1+\rho)^{2}\right] \operatorname{tg}^{2}(\varphi)\right\},
\end{aligned}
$$

где $\rho$ и $\varphi$ определены выше.
Чтобы убедиться, влияет или не влияет $\varphi$ на $\varepsilon$, были дополнительно измерены эллипсометрические углы $\Psi_{\text {exp }}$ и $\Delta_{\exp }$ в диапазоне $\varphi=50-65^{\circ}$ с шагом $5^{\circ}$. Далее, используя выражение (2), были рассчитаны действительная и мнимая части $\varepsilon$ слоя наночастиц $\mathrm{Ag}$, которые представлены на рис. 4 в зависимости от энергии фотона $E$.

Как видно на рис. 4 , оба спектра $\varepsilon_{1}$ и $\varepsilon_{2}$ мало зависят от угла падения излучения, поэтому можно считать, что полученный слой $\mathrm{Ag}$ имеет свою собственную диэлектрическую функцию. Следует отметить, что полученные многоугловые спектральные зависимости слоя наночастиц серебра по значениям параметров $\varepsilon_{1}, \varepsilon_{2}$ и характеру их изменения существенно отличаются от $\varepsilon_{1}$ и $\varepsilon_{2}$ для структуры серебра [15]. Кроме того, как на спектральной зависимости диэлектрической функции (рис. 4), так и в спектре эллипсометрических углов (рис. 3) формируется пик при $\lambda=326$ нм $(E=3.8$ эВ), который проявляется при исследовании оптических спектров тонких пленок серебра [17] и связан с возбуждением поверхностных плазмонов коллективного типа [18].

Особое внимание было уделено исследованию стабильности оптических параметров слоя наночастиц се-
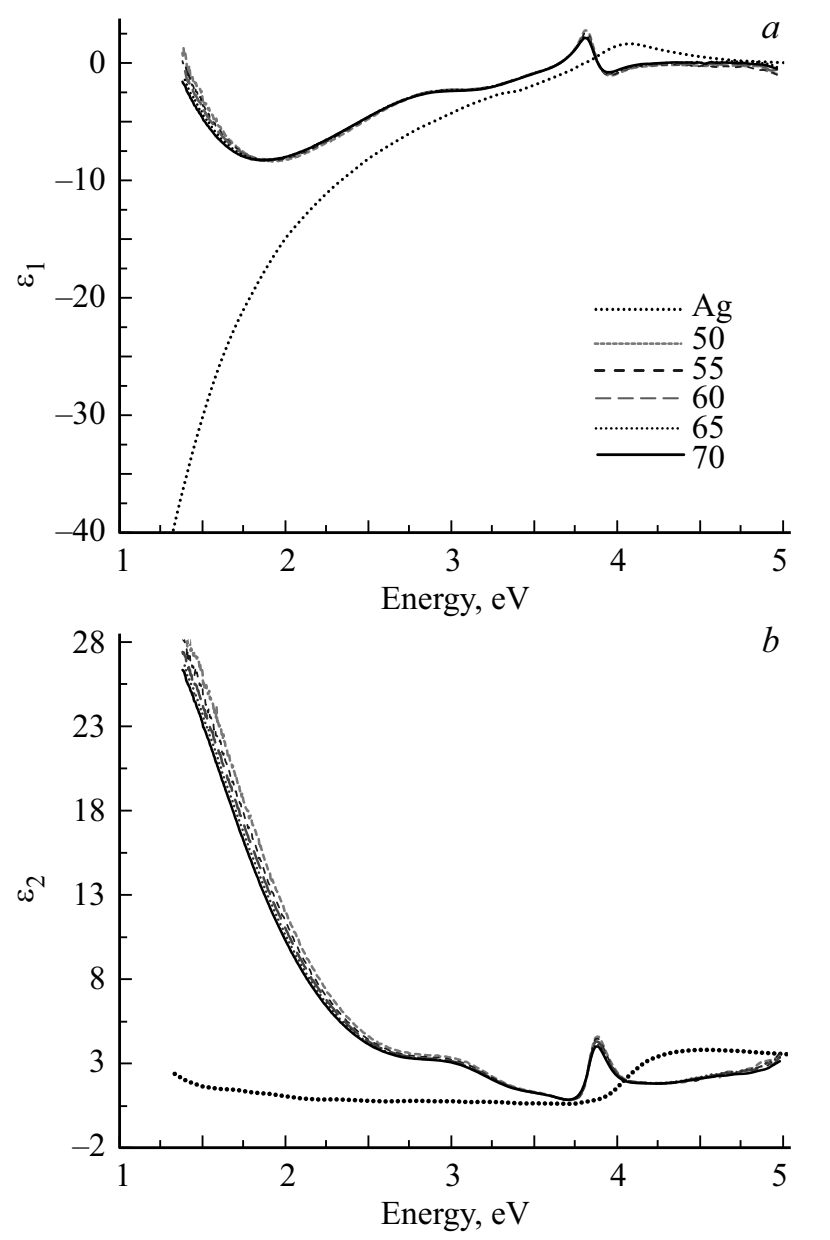

Рис. 4. Действительная $(a)$ и мнимая $(b)$ части комплексной диэлектрической функции $\varepsilon$ для слоя наночастиц серебра на поверхности кремния, определенные из выражения (2) для углов падения излучения $\varphi$ (цифры у линий). Для сравнения представлены $\varepsilon_{1}$ и $\varepsilon_{2}$ для серебра по данным справочника [15]. 
ребра при его осаждении. Сразу же после того как образец промывали и сушили при комнатной температуре на воздухе, были измерены эллипсометрические спектры, которые были неизменными в течение нескольких часов. Важное отличие используемой нами технологии от метода вакуумного осаждения состоит в том, что структура наночастиц Ag была образована в результате воздействия химического раствора, который препятствует образованию оксидов на границе раздела между наночастицей и раствором Ag.

Поскольку настоящая работа была нацелена на изучение оптических свойств поверхностных наноструктур, формирующихся в процессе МСХТ, интерпретация результатов для первой стадии МСХТ (получение и исследование слоя $\mathrm{Ag}$ в качестве маски-катализатора) была ограничена определением количественной характеристики в виде диэлектрической функции для наиболее простой модели „эффективной подложки“. Исследование оптических свойств слоя наночастиц $\mathrm{Ag}$ с применением других оптических моделей, включая модели эффективной среды, а также возможное присутствие оксида, будет представлено в отдельной публикации.

\section{4. Заключение}

В результате химического осаждения получен слой самоорганизующихся наночастиц $\mathrm{Ag}$, который будет обеспечивать дальнейшее селективное каталитическое травление $\mathrm{Si}$. C помощью растрового электронного микроскопа исследована морфология слоя наночастиц серебра толщиной 40-60нм, а методом спектральной эллипсометрии $(\lambda=250-900$ нм $)$ впервые измерены спектры эллипсометрических углов нанослоев $\Psi$ и $\Delta$ для такого типа структур. На основе этих спектров определена собственная комплексная диэлектрическая функция, которая отличается от $\varepsilon$ металлического серебра, и выявлен характерный пик плазмонного резонанса в УФ-части спектра.

Таким образом, исследована возможность получения с высокой воспроизводимостью и стабильных во времени слоев Ag заданной морфологии и их оптической характеризации в виде диэлектрических функций. Исследования оптических свойств слоев нанонитей $\mathrm{Si}$, формирующихся в последующих стадиях МСXТ, будут опубликованы во второй части этой работы (в отдельной статье).

Исследование выполнено при финансовой поддержке РФФИ в рамках научного проекта № 17-02-01116 А с использованием оборудования центра коллективного пользования „Материаловедение и диагностика в передовых технологиях“.

\section{Список литературы}

[1] V. Schmidt, H. Riel, S. Senz, S. Karg, W. Riess, U. Gosele. Small, 2, 85 (2005).

[2] F. Priolo, T. Gregorkiewicz, M. Galli, T.F. Krauss. Nature Nanotechnology, 9, 19 (2014).
[3] B. Tian, X. Zheng, T.J. Kempa, Y. Fang, N. Yu, G. Yu, J. Huang, C.M. Lieber. Nature, 449, 885 (2007).

[4] F. Patolsky, C. Zheng, C.M. Lieber. Nature Protoc., 1, 1711 (2006).

[5] K. Booker, S. Rahman, T-K. Chong, R. Mankelow, K. Weber, A. Blakers. IEEE J. Photovolt., 5, 2156 (2015).

[6] W. McSweeney, H. Geaney, C. O’Dwyer. Nano Research, 8, 1395 (2015).

[7] Min Lv, Shao Su, Yao He, Qing Huang, Wenbing Hu, Di Li, Chunhai Fan, Shuit-Tong Lee. Adv. Mater., 22, 5463 (2010).

[8] Hee Han, Zhipeng Huang, Woo Lee. Nanotoday, 9, 271 (2014).

[9] Ellipsometry at the Nanoscale, ed. by M. Losurdo, K. Hingerl (N.Y.-Dordrecht-London, Springer, 2013) p. 1.

[10] T.W.H. Oates, H. Sugime, S. Noda. J. Phys. Chem., 113, 4820 (2009).

[11] S. Marsillac, S.A. Little, R.W. Collins. Thin Sol. Films, 519, 2936 (2011).

[12] T.W.H. Oates, H. Wormeester, H. Arwin. Progr. Surf. Sci., 86, 328 (2011).

[13] В.А. Швец, Е.В. Спесивцев, С.В. Рыхлицкий, Н.Н. Михайлов. Рос. нанотехнол., 4, 201 (2009).

[14] Р. Аззам, Н. Башара. Эллипсометрия и поляризованный свет (М., Мир, 1981) с. 316. [Пер. с англ. R.M.A. Azzam, N.M. Bashara. Ellipsometry and Polarized Light (Amsterdam-N.Y.-Oxford, North-Holland Publ. Co, 1977).]

[15] Handbook of Optical Constants of Solids, ed. by E.D. Palik (N.Y., Academic Press, 1985) p. 804.

[16] D.E. Aspnes. Thin Sol. Films, 89, 249 (1982).

[17] A.J. McAlister, E.A. Stern. Phys. Rev., 132 (4), 1599 (1963).

[18] В.В. Климов. Наноплазмоника (М., Физматлит, 2009) гл. 4 , с. 69.

Редактор Г.А. Оганесян

\section{Surface nanostructures formed at the early stages of metal-assisted chemical etching of silicon. Optical properties of silver nanoparticles}

Yu.A. Zharova, V.A. Tolmachev, A.I. Bednaya,

S.I. Pavlov

loffe Institute, 194021 St. Petersburg, Russia

Abstract The work consists of two parts and it is devoted to the study of nanostructures, which were formed by 3-step process of metal-assisted chemical etching (MACE) of silicon. In the first part of this work the process of chemical deposition of a layer of $\mathrm{Ag}$ nanoparticles was investigated and it is reported in present article. The Ag nanoparticles self-assembled on the surface of the silicon wafer (first step of MACE). This layer is, on the one hand, a catalyst for conducting subsequent etching of silicon, and on the other hand serves as a kind of mask for the formation of a certain topology of the emerging Si nanowires. The morphology of a layer of silver nanoparticles $(40-60 \mathrm{~nm}$ thick) was studied with use of scanning electron microscope. For $\mathrm{Ag}$ nanolayers the spectra of ellipsometric angles $\Psi$ and $\Delta$ were measured using spectroscopic ellipsometry $(\lambda=250-900 \mathrm{~nm})$. The complex dielectric function of the obtained Ag layer was determined. The characteristic peak of plasmon resonance was observed in the UV part of the spectrum. Investigations of the optical properties of the layers of Si nanowires formed in the early stages of MACE will be published in the second part of this work (in a separate article). 